\title{
THE PENDULAR-FUNICULAR LIQUID TRANSITION IN SNOW
}

\author{
By A. Denoth
}

(Institut für Experimentalphysik der Universität Innsbruck, A-6o2o Innsbruck, Austria)

Abstract. The way free water is distributed around contact points of ice grains is recorded by measuring the dielectric constant of the porous system which constitutes snow. Within the saturation range of $11 \%$ to $15 \%$ of the pore volume, a transitional range from the "pendular" to the "funicular" mode of distribution of free water occurs. By measuring the drainage-flow of free water through snow, additional information as to the upper limit of the pendular distribution is obtained. This upper limit is reached at a saturation of approximately $14 \%$ of the pore volume.

Résumé. La transition de la répartition pendulaire à la repartition funiculaire de l'eau libre de la neige. La nature de la répartition de l'eau libre autour de contacts de grains de glace est établie en mesurant la constante diélectrique du système poreux de la neige. Dans la zone de saturation entre $\mathrm{I}$ i $\%$ et $\mathrm{I}_{5} \%$ du volume des pores se forme une zone de transition de la répartition "pendulaire" à la répartition "funiculaire" de l'eau libre. Par mesure du passage de l'eau libre au travers du milieu poreux neige, on obtient des informations supplémentaires sur la limite supérieure de la répartition pendulaire. Pour cette limite supérieure on obtient un degré de saturation d'environ $14 \%$ du volume des pores.

Zusammenfassung. Der Ubergang von der "pendular" in die "funicular" Verteilung des freien Wassers im Schnee. Die Art der Anordnung des freien Wassers um Kontaktstellen von Eiskörnern wird durch die Messung der Dielektrizitätskonstante des porösen Systems Schnee erfasst. Im Sättigungsbereich von II \% bis $15 \%$ des Porenvolumens bildet sich eine Übergangszone von der "pendular" in die "funikular" Verteilung des freien Wassers aus. Durch Messung des Sickerflusses des freien Wassers durch das poröse Medium Schnee erhält man eine zusätzliche Information über die Obergrenze der "pendular" Verteilung. Für diese Obergrenze ergibt sich ein Sättigungswert von ungefähr $14 \%$ des Porenvolumens.

\section{List OF SYMBOLS}

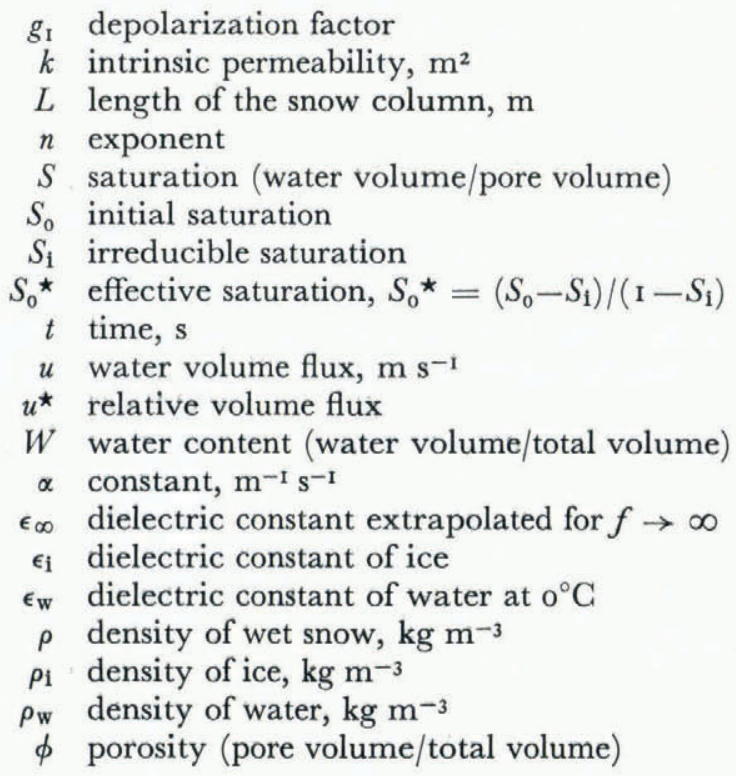

\section{INTRODUGTION}

The water-saturation of a natural snow cover varies, in general, from zero to approximately $20 \%$ of the pore volume. In this case two essentially different types of distribution of free water can be observed: the pendular mode and the funicular mode of distribution. Pendular 
distribution covers the range of very low saturations corresponding to a water film on an ice grain adsorbed to a degree of saturation where the various isolated water menisci surrounding the ice grains flow together into complicated structures. Funicular distribution covers the range from the upper limit of the pendular mode to the total saturation of the pore volume. The change from the pendular to the funicular mode takes place at a saturation of between $10 \%$ and $20 \%$ of the pore volume. As there is a considerable change in the distribution of water during this transition from the pendular to the funicular mode, this also leads to a change in the physical characteristics of the snow-cover.

It is the purpose of this paper to determine the saturation regime in which the transition from the pendular to the funicular mode of water distribution in snow appears. For this purpose both the dielectric constant of wet snow and the drainage of water from snow columns were carefully analysed.

\section{DieleGtric MEASUREMENTS}

A method particularly suitable for field measurements to find the distribution of free water in snow consists in measuring the dielectric constant. Theoretical studies have shown that the dielectric constant of heterogeneous mixtures is essentially influenced by the way the various components are distributed. Here the mixing formula of Polder and van Santen (1946) is particularly suitable for calculating the dielectric constant $\epsilon_{\infty}$ of the porous system which constitutes snow from the dielectric constant of the components ice, air, and water, from their parts per volume, and a depolarization factor (Denoth and Schittelkopf, 1978). The mixing formula of Polder and van Santen in an adapted form for the system of snow reads as follows:

$$
\epsilon_{\infty}\left[\mathrm{I}-\frac{W}{3}\left(\epsilon_{\mathrm{W}}-\epsilon_{\mathrm{d}}\right)\left(\frac{2}{\epsilon_{\infty}+\left(\epsilon_{\mathrm{W}}-\epsilon_{\infty}\right) g_{\mathrm{I}}}+\frac{\mathrm{I}}{\epsilon_{\infty}+\left(\epsilon_{\mathrm{W}}-\epsilon_{\infty}\right)\left(\mathrm{I}-2 g_{\mathrm{I}}\right)}\right)\right]-\epsilon_{\mathrm{d}}=0,
$$

where

$$
\epsilon_{\mathrm{d}}=\frac{3 \epsilon_{\mathrm{i}}(\mathrm{I}-W)+2(\mathrm{I}-\phi) \epsilon_{\mathrm{i}}\left(\epsilon_{\mathrm{i}}-\mathrm{I}\right)}{3 \epsilon_{\mathrm{i}}(\mathrm{I}-W)-(\mathrm{I}-\phi)\left(\epsilon_{\mathrm{i}}-\mathrm{I}\right)} .
$$

The geometrical configuration of water inclusions in the dry-snow matrix changes with increasing water content and so consequentiy does the depolarization factor $g_{1}$. In Figure I the depolarization factor $g_{1}$ calculated from the Polder and van Santen model (Equation (I)) is plotted against saturation $S$. The dielectric constant of snow samples with different liquid contents was measured by a capacitance bridge within a frequency range from $\mathrm{r}$ oo $\mathrm{kHz}$

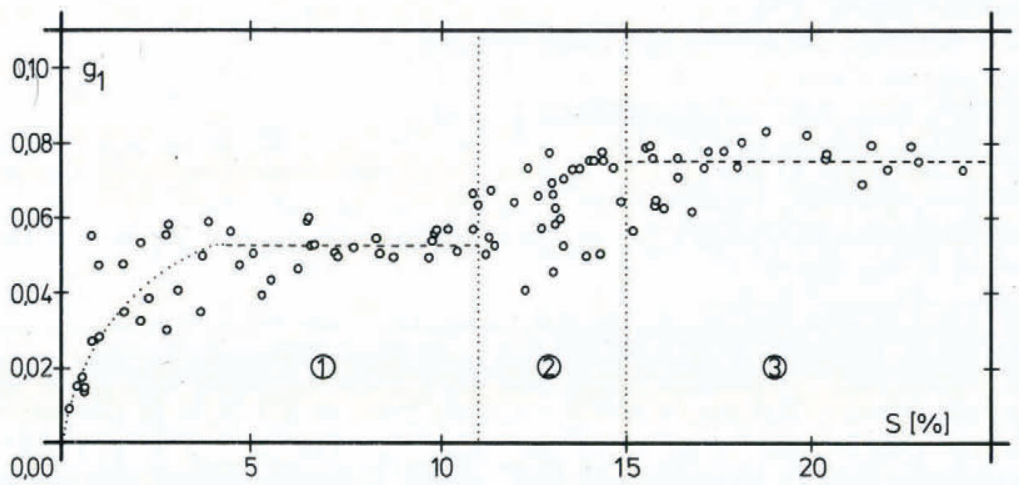

Fig. 1 . The depolarization factor $g_{1}$ as a function of saturation $S . \quad I:$ pendular regime; $2:$ transitional zone; $3:$ funicular regime. 
up to $20 \mathrm{MHz}$, and the dielectric constant $\epsilon_{\infty}$ required for Equation (I) was obtained by extrapolation for $f \rightarrow \infty$ according to the Cole-Cole model (Ambach and Denoth, 1972). The free-water content $W$ was obtained from a freezing calorimeter with an accuracy of $\pm 0.5 \%$ by volume. The density $\rho$ of wet snow was found by weighing; porosity $\phi$ and saturation $S$ were calculated from:

$$
\begin{aligned}
& \phi=\mathrm{r}-\left(\rho-\rho_{\mathrm{w}} W\right) / \rho_{\mathrm{i}}, \\
& S=W / \phi .
\end{aligned}
$$

Figure I shows two significantly different arrangements of free water: within the saturation range $0 \leqslant S \leqslant$ I I \% with a depolarization factor $g_{\mathrm{I}} \approx 0.053$ an arrangement corresponding to the pendular mode of distribution, and within the saturation range of $15 \% \leqslant S \leqslant 25 \%$ with a depolarization-factor $g_{1} \approx 0.076$ an arrangement corresponding to the funicular mode of distribution with complicated aggregates formed by the various water menisci flowing together. In between, i.e. within the saturation range from I $\% \leqslant S \leqslant \mathrm{I}_{5} \%$, a transitional range from the pendular into the funicular distribution is formed. In the case of very low saturations $(S<4 \%)$ the depolarization factor decreases towards zero. This means, that in the case of such low saturations the shape of the water inclusions tends more and more to flat discs, forming a borderline case of oblate spheroids when $g_{\mathrm{I}}=0$.

It is obvious that a change in water distribution, as mentioned above, affects the flow characteristics of water in snow. Consequently, additional information as to the upper limit of the pendular distribution can be obtained by measuring the dependence on saturation of flux of the water volume from a snow column. Therefore, drainage experiments were carried out using old, natural snow, repacked in tubes, with saturations of up to $18 \%$ of the pore volume. The outflowing water volume was continuously recorded by a capacitative level pick-up.

\section{Drainage MEASUREMENTS}

According to the gravity-flow theory (Colbeck, I97I) one obtains for the water volume flux $u$ of a draining snow column with an initially constant saturation $S_{0}$ throughout the snowcolumn length (Denoth and others, I979):

$$
u= \begin{cases}u_{0}=\alpha k S_{0}^{\star n}, & t \leqslant t_{0}, \\ {\left[\phi L\left(\mathrm{I}-S_{\mathrm{i}}\right) / n(\alpha k)^{\mathrm{I} / n}\right]^{n /(n-\mathrm{I})} t^{n /(\mathrm{I}-n)},} & t_{0} \leqslant t,\end{cases}
$$

where $t_{0}$ is that time in which a constant flux $u_{0}$ appears and is given by:

$$
t_{0}=L \phi\left(\mathbf{I}-S_{\mathrm{i}}\right) S_{0} \star^{\star}-n(n \alpha k)^{-1} .
$$

For comparison purposes, however, it is practical to rewrite Equation (2a) in dimensionless form:

$$
u^{\star}=u / u_{0}= \begin{cases}\mathrm{I}, & t \leqslant t_{0}, \\ \left(t / t_{0}\right)^{n /(\mathrm{I}-n)}, & t \geqslant t_{0} .\end{cases}
$$

In Figure 2 the relative water-volume flux $u^{\star}$ (represented by data points) from snow columns* with'saturations of $S_{0}=11.6 \%$ (symbol: - ), $S_{0}=12.7 \%$ (symbol: $\triangle$ ), and $S_{0}=14.5 \%$ (symbol: 0 ) respectively is plotted against time (in units of $t_{0}$ ). As a change in flow characteristics is expected when water distribution changes, only drainage experiments with initial saturations corresponding to the transitional zone (cf. Fig. I) are shown. In addition, the theoretical profile according to Equation (2b) is given (solid line). Satisfactory conformity

\footnotetext{
* Homogeneous old snow, repacked in tubes, with an average grain-size of $\mathrm{I} \mathrm{mm}$.
} 
with the experiments is obtained only for saturations less than approximately $13 \%$. For saturations higher than approximately $14 \%$, a substantially higher flux becomes apparent at the beginning than one would have expected according to the gravity-flow theory. This can be explained by the formation of an additional flux in an unstable channel system with total saturation, formed by coalescing water menisci during the transition from the pendular to the funicular regime (Denoth and others, 1979). Consequently, a saturation of about $14 \%$ of the pore volume can be assumed as the upper limit of pendular distribution.

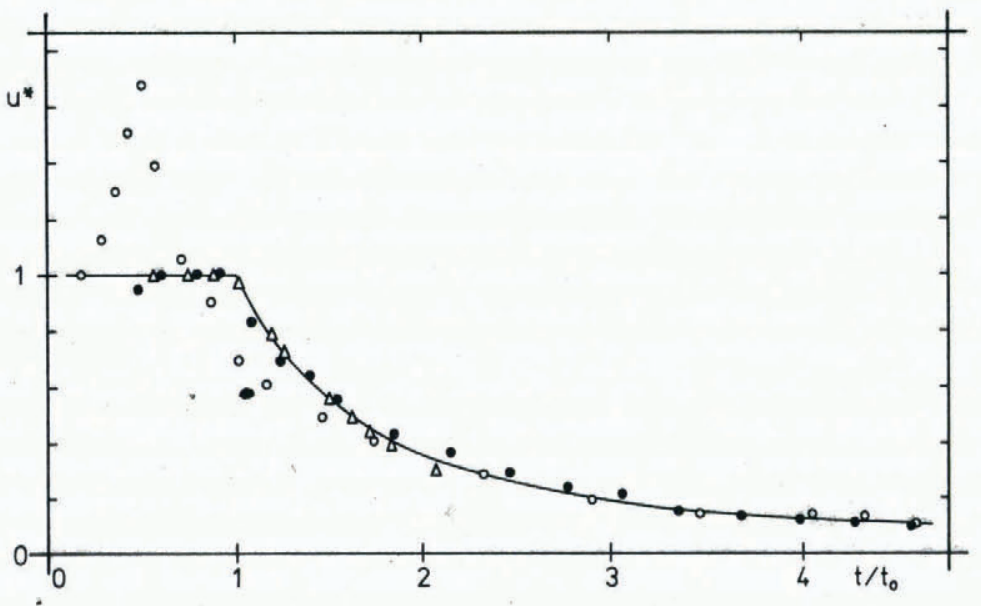

Fig. 2. Plot of relative water volume flux $u^{\star}$ against time (in units of $t_{0}$ ) according to the gravity-flow theory (Equation (2b)) compared with experimental data of relative volume flux from snow-columns with different initial saturations: $S_{0}=11.6 \%$ $(\mathrm{O}), S_{0}=12.7 \%(\triangle)$, and $S={ }_{0} 14.5 \%(O)$.

\section{Discussion}

By measuring the dielectric constant, a relationship between the distribution of water inclusions and the water saturation is obtained in the form of the depolarization factor $g_{1}$. In Equation ( $\mathrm{r}$ ) the depolarization factor accounts for the shape of inclusions:

$$
g_{1}=\frac{1}{2} a_{1} a_{2} a_{3} \int_{0}^{\infty}\left[\left(a_{1}^{2}+s\right)\left(a_{2}^{2}+s\right)\left(a_{3}^{2}+s\right)\right]^{-\frac{1}{2}}\left(a_{1}^{2}+s\right)^{-1} \mathrm{~d} s,
$$

$a_{1}, a_{2}$, and $a_{3}$ being the semi-axes of elliptic inclusions. Although the arrangement of free water around the contact points of ice grains (both in the pendular and in the funicular regime) does not appear in the form of ellipsoids or spheroids, it can be assumed that in the case of the low water saturations of a natural snow cover the arrangement of free water is somewhat disc-shaped. Thus the water menisci can approximately be described as oblate spheroids, so that the depolarization-factor $g_{\mathrm{r}}$ does not reflect quantitatively the geometrical shape of the inclusions, but it offers information as to the relationship between the geometry of distribution and the water saturation.

In the case of greater saturations, several water menisci flow together into complicated water structures (funicular regime), as has already been mentioned. This can be seen from a change in the depolarizing factor from $g_{\mathrm{I}} \approx 0.053$ to $g_{\mathrm{I}} \approx 0.076$ when the saturation increases from $1 \mathrm{I} \%$ to $15 \%$. Here it must be noted, however, that with a growing percentage by volume of water, electric interactions between the various water aggregates can no longer be 
neglected. This limits the application of the basic mixing formula (Equation (I)) to saturations smaller than $20 \%$, which is the case for a natural snow cover.

The drainage experiments show that the flow characteristics of water change substantially if the saturation changes from i $\%$ to $15 \%$ : for saturations higher than approximately $14 \%$ of the pore volume an additional flow in saturated channels is formed. A saturation of I I \% is at the lower end, and the saturation of $15 \%$ at the upper end, of the transitional range from the pendular to the funicular regime.

From both the dielectric measurements and the drainage experiments it results that a saturation of about $14 \%$ can be assumed as the upper limit of the pendular mode of distribution of water in snow of an advanced degree of metamorphism. This broadly corresponds to an estimation of the upper limit of the pendular regime in snow as $14 \%$ of the pore volume given by Colbeck (1973) based on the theoretical work of Smith (1933). However it is likely that the value of the liquid content at the transition will vary with the degree of metamorphism of the snow.

\section{AGKnowledgements}

The research reported herein has been sponsored in part by the U.S. Army through its European Research Office under Project number DA-ERO 76-G-o38. Thanks are given to the Kuratorium der Alpinen Forschungsstelle Obergurgl der Universität Innsbruck for supporting further field measurements.

MS. received I February 1979 and in revised form 5 March 1979

\section{REFERENCES}

Ambach, W., and Denoth, A. 1972. Studies on the dielectric properties of snow. Zeitschrift für Gletscherkunde und Glazialgeologie, Bd. 8, Ht. 1-2, p. $113-23$.

Colbeck, S. C. 1971. One-dimensional water flow through snow. U.S. Cold Regions Research and Engineering Laboratory. Research Report 296.

Colbeck, S. C. 1973. Theory of metamorphism of wet snow. U.S. Cold Regions Research and Engineering Laboratory. Research Report 313.

Denoth, A., and Schittelkopf, H. 1978. Mixing formulas for determining the free water content of wet snow from measurements of the dielectric constant. Zeitschrift für Gletscherkunde und Glazialgeologie, Bd. 14, Ht. 1, p. 73-8o.

Denoth, A., and others. 1979. Study of water drainage from columns of snow, by A. Denoth [and 5 others]. U.S. Cold Regions Research and Engineering Laboratory. Report 79-1.

Polder, D., and Santen, J. H. van. 1946. The effective permeability of mixtures of solids. Physica, Vol. 12, No. 5, p. 257-71.

Smith, W. O. 1933. The final distribution of retained liquid in an ideal uniform soil. Physics, Vol. 4, No. 12, p. $425-38$. 